\title{
ВТРАТА СТІЙКОСТІ ОБОЛОНОК ПОКРИТТЯ 3 ДОПУСТИМИМИ ВІДХИЛЕННЯМИ ПОВЕРХНІ
}

\section{BUCKLING OF COATING SHELL WITH PERMISSIBLE SURFACE DEFLECTION}

Коломійчук Г.П., к.т.н., доцент, Майстренко О.Ф., к.т.Н., доцент, Коломійчук В.Г., магістр, Коломійчук В.Г., студентка (Одеська державна академія будівництва та архітектури, м. Одеса)

Kolomiychuk G.P., Ph.D. in Engineering, Associate Professor, Maystrenko O.F., Ph.D. in Engineering, Associate Professor, Kolomiychuk V.G., Master, Kolomiychuk V.G., student (Odessa State Academy Civil Engineering and Architecture, Odessa)

Виконано огляд досліджень по визначенню впливу відхилень поверхні побудованих великопролітних оболонок покриття на їх стійкість. Наведені результати числового експерименту, що показують найбільш небезпечні ділянки оболонки 3 відхиленнями поверхні та отримані прогини втрати стійкості.

It is known that the initial imperfections of the shape of the surface of the shell (defects during manufacture) affect the magnitude of the critical load. The analysis of experimental results of shell experiments showed that at an amplitude of imperfection which equal to the thickness of the shell, the critical load decreases by almost four times.

The solution of the problem of buckling of elastic shell to explain the differences between the theoretical and experimental data is made using the method of initial imperfections. According to this method, instead of the set of all initial defects of the shell, the initial equivalent deflection from the ideal form $W_{0}^{e}$ is introduced.

To detect the minimum edge critical load of a double positive curvature shallow shell, a form of imperfection on the plan of the shell was identified as a circular localized dent.

The system of differential nonlinear equations in displacements is given to a system of algebraic nonlinear equations using the finite difference method. 
The position of the local limited dent on the shell plan is determined by the points of the finite-difference grid, which coincide with the centers of the dent $(i, j)$. The minimum dimensions of the dent on the shell plan depend on the distance between the nodes of the finitedifference grid and are assigned so that the number of nodes in the direction of the coordinate axes $\mathrm{X}(\mathrm{Y})$ is at least three in the middle of the dent. In the knots that got into the dent, geometry deviations of the denture shell from the mid-surface of the shell are determined and used as input data during the formation of a solving system of equations.

A numerical experiment is performed for a symmetric dent placement on a shell plan (shell center: $i=7, j=7$ ). Fixing of a square shell of a positive curvature on all four sides is hinged.

An overview of the studies of built shell coatings shows that it is necessary to improve the methods of their construction and to introduce limitations on defects obtained as a result of construction. The results of a numerical experiment for determining the stability of a shell of a positive curvature with initial imperfections indicate the influence of these imperfections for different curvatures and the different location of imperfections.

Ключові слова: втрата стійкості, залізобетонна оболонка, початкові недосконалості, прогини, кривина.

Keywords: buckling, reinforced concrete shell, initial imperfections, deflections, curvature.

Вступ. Сучасні унікальні великопролітні будівлі та споруди зводяться з надміцних матеріалів, а відношення товщини перерізу до довжини прольоту зменшується. Розрахунок втрати стійкості тонкостінних оболонок покрить постійно удосконалюється за отриманими результатами нових експериментальних досліджень моделей та натурних конструкцій, а також за допомогою чисельних експериментів математичних моделей, що описують реальну поверхню конструкції під час експлуатації.

Аналіз останніх досліджень та публікацій. Відомо, що початкові недосконалості форми поверхні оболонки (дефекти під час виготовлення) впливають на величину критичного навантаження. Аналіз експериментальних результатів дослідів оболонок, виконаний у роботах $[1,2]$, показав, що при амплітуді недосконалості, що дорівнює товщині оболонки, критичне 
навантаження зменшується майже в чотири рази.

У поправках до рекомендацій IASS [3] запропоновано вважати, що розрахункова величина початкової недосконалості складається 3 недосконалості $w_{0, \text { calc }}$ (згинні моментні деформації) та $w_{0, a c c}-$ недосконалості, що залежить від точності виготовлення конструкції. Недосконалість, що враховує технологічні дефекти виготовлення, визначається за емпіричною формулою:

$$
w_{0, a c c}=0,05 \delta+(R \cdot a / 2000) /\left(\kappa_{l} / 1000+1000 / \kappa_{l}\right)
$$

де $\delta$ - товщина оболонки; $R$ - радіус кривини серединної поверхні; $\kappa_{l}=R / \delta$; параметр “ $a$ ” залежить від жорсткості опалубкової форми: $a=1$ - для жорсткої форми, яка забезпечує досить точне виготовлення оболонки; $a=6$ - для гнучкої опалубкової форми.

Сумарну недосконалість знаходять за формулою:

$$
w_{0}=\left(\mathrm{w}_{0, \text { calc }}^{2}+1,4 w_{0, \text { calc }} w_{0, a c c}+w_{0, a c c}\right)^{1 / 2}
$$

Кренцке М. [4] проводив серію випробувань 26 півсфер 3 сплавів алюмінію, які спиралися на підкріплені шпангоутами циліндри, сконструйовані 3 метою створення мембранних граничних умов. Оболонки були товстостінними при значеннях $\mathrm{R} / \mathrm{h}=11 \div 107$. Всі зразки ретельно оброблялися 3 мінімальними допусками на виготовлення (максимальні відхилення в товщині і від форми сферичної поверхні становили відповідно 0,75\% і 0,00001 від радіуса). Майже у всіх випадках оболонки втрачали стійкість шляхом утворення «ямки» в зонах, далеких від опори, що вказувало на досягнення поставленої мети. Випробувані два додаткових зразки $(\mathrm{R} / \mathrm{h}=165)$ були виготовлені ще більш ретельно - один 3 них втратив стійкість при 73\%, а інший при $90 \%$ від класичного критичного тиску.

Дослідження сталевих штампованих сферичних оболонок 3 технологічними вм'ятинами $(\mathrm{R} / \mathrm{h}=120 \div 136)$ представлені в роботі [5]. Після проведення ретельних обмірів початкових недосконалостей моделі були випробувані на стійкість зовнішнім гідростатичним тиском. Результати дослідів показали, що втрата стійкості відбувалася в тому місці, де були найбільші відхилення від сферичної форми.

Результати контрольної геодезичної зйомки поверхні оболонки додатної кривини [6] покриття ринку в м. Мінську з розмірами в плані $103 \times 103$ м показали, що середнє відхилення центральної частини поля оболонки від проектного положення склало - 23,3 мм, а середньоквадратичне відхилення $\pm 38,4$ мм, відповідно для 
контурних елементів $+26,75$ мм та $\pm 31,2$ мм. Аналіз робіт по зведенню збірно-монолітної аглопоритозалізобетонної оболонки показав, що сукупність функціональних та технологічних похибок превисила допустимі розрахунком величини відхилення поверхні оболонки від проектного положення.

Зільбер Я.М. [7] виконав виміри фактичних геометричних недосконалостей залізобетонних збірних оболонок покриття додатної кривини конструкції ПІ-1. Виміри перевищення поля плит або кондукторів над номінальним рівнем виконувалися за допомогою нівеліра НВ-1 та спеціальної рейки, обладнаної для підвищення точності вимірів штирем та виском. Таким чином, отримана відмітка відповідала саме тій точці, де виконувався вимір. Геометричні розміри визначалися за допомогою металевої рулетки.

Проведені дослідження дозволили зробити декілька висновків про характер початкових недосконалостей реальних оболонок: практично ні де математичне очікування не дорівнює нулю, а це свідчить про те, що існують деякі систематичні фактори, які впливають на статистичні властивості конструкцій; - статистичні характеристики геометричних розмірів плит оболонок мають розкид, що значно перевищує існуючі нормативи, а тому це необхідно враховувати для призначення коефіцієнту перевантаження та оцінки якості; - тривалий досвід експлуатації оболонок з значними початковими недосконалостями показує, що необхідно дати науково обгрунтовані методи призначення нормативів на точність виготовлення та монтаж оболонок.

В роботі [8] наведені способи по визначенню можливих відхилень вузлів від проектного положення в сіткових металевих просторових оболонках. Найбільш близькими до реальних великопрольотних просторових стрижневих систем слід вважати відомості, отримані на основі комп'ютерного моделювання дійсної форми стрижневих систем з урахуванням випадкової мінливості розмірів конструкцій.

Цілі і завдання. Розвиток будівництва унікальних великопролітних будівель та споруд у світі набрав неабияких темпів, а обгрунтованих рекомендацій по розрахунку стійкості реальних побудованих оболонок немає. В статті виконано огляд досліджень по визначенню впливу відхилень поверхні побудованих великопролітних оболонок покриття на їх стійкість. Наведені результати числового експерименту, що показують найбільш 
небезпечні ділянки оболонки з відхиленнями поверхні та отримані прогини втрати стійкості.

Основна частина. Вирішення задачі втрати стійкості пружних оболонок для пояснення розбіжностей теоретичних та експериментальних даних виконано 3 використанням методу початкових недосконалостей. Згідно 3 цим методом замість сукупності всіх початкових недосконалостей оболонки, вводиться початкове еквівалентне відхилення від ідеальної форми $W_{0}^{e}$. Зазвичай величину $W_{0}^{e}$ розкладаються в функціональний ряд 3 невідомими коефіцієнтами і досліджують іi вплив на величину критичного навантаження. Але через те, що початкові недосконалості $€$ випадковим, визначення цих коефіцієнтів стає деякою самостійною задачею, пов'язаною 3 конкретною технологією зведення оболонки i статистичним аналізом недосконалостей. Перспективнішим видається інший шлях. Можна задати обмеження на величину $W_{0}^{e}$ i знайти такі значення коефіцієнтів, які найбільшою мірою зменшують критичне навантаження при цих обмеженнях [9].

Численні виміри реальних конструкцій показали, що фактичні початкові недосконалості не мають регулярного розподілення, а $\epsilon$ локальними, поширюючись в обмеженій області.

Для виявлення мінімального граничного критичного навантаження пологої оболонки подвійної додатної кривини виділили форму недосконалості на плані оболонки в вигляді круглої локальної обмеженої вм'ятини [1].

Система диференційних нелінійних рівнянь у переміщеннях приведена до системи алгебраїчних нелінійних рівнянь 3 використанням методу кінцевих різниць [1].

Положення локальної обмеженої вм'ятини на плані оболонки визначається точками кінцево-різницевої сітки, що збігаються 3 центрам вм'ятини $(i, j)$. Мінімальні розміри вм'ятини на плані оболонки залежать від відстані між вузлами кінцево-різницевої сітки та назначаються так, щоб кількість вузлів у напрямку координатних осей $X(Y)$ була не менше трьох у середині області вм'ятини. У вузлах, що потрапили у вм'ятину, визначаються аплікати відхилення геометрії оболонки вм'ятини від серединної поверхні оболонки і використовуються як вихідні дані під час формування розв'язуючої системи рівнянь [1]. 
Ідеальні оболонки додатної Гауссової кривини постійної товщини під дією рівномірно розподіленого «мертвого» навантаження втрачають стійкість по-різному, залежно від параметра кривини [10]. Будемо розрізняти пологі оболонки по величині параметру кривини $\left(k=a^{2} /\left(R_{1} h\right)+b^{2} /\left(R_{2} h\right)\right.$, де $a-$ довжина оболонки; $b$ - ширина оболонки; $h$ - товщина оболонки; $R_{l}, R_{2}-$ радіуси кривини оболонки). Так, $k<60$ - мала; $60<k<200-$ середня; $200<k<1000$ - велика; $k>1000$ - дуже велика. Оболонки малої кривини втрачають стійкість 3 прохлопування всього поля; середньої, великої і дуже великої кривини - випучуються 3 утворенням ізольованої одиночної вм'ятини в куті, займаючи не більше 10 \% поверхні оболонки.

Числовий експеримент виконано для симетричного випадку розміщення вм'ятини на плані оболонки (центр оболонки: $i=7, j=7$ ). Закріплення квадратної оболонки додатної кривини по всіх чотирьох сторонах - шарнірне. Під час переміщення локальної вм'ятини по плану оболонки визначалося критичне навантаження, а також форма втрати стійкості для різних кривин. В таблицях наведені прогини від дії четвертої частини (таблиця 2) та усього критичного навантаження (таблиця 1).

Таблиця 1

Максимальний відносний прогин втрати стійкості оболонок

\begin{tabular}{|c|c|c|c|c|c|c|}
\hline \multirow{2}{*}{$\begin{array}{c}\text { Вузол } \\
\text { центру } \\
\text { вм'ятини }\end{array}$} & \multicolumn{7}{|c|}{ Максимальний відносний прогин } \\
\cline { 2 - 7 } & 40 & 120 & 200 & 400 & 600 & 800 \\
\hline \multirow{2}{*}{ немає } & $\begin{array}{c}1,199 \\
/ 7,7 /\end{array}$ & $\begin{array}{c}0,827 \\
/ 3,3 /\end{array}$ & $\begin{array}{c}0,655 \\
/ 3,3 /\end{array}$ & $\begin{array}{c}0,656 \\
/ 2,2 /\end{array}$ & $\begin{array}{c}0,844 \\
/ 2,2 /\end{array}$ & $\begin{array}{c}1,056 \\
/ 2,2 /\end{array}$ \\
\hline \multirow{2}{*}{2,2} & $\begin{array}{c}1,254 \\
(7,7)\end{array}$ & $\begin{array}{c}0,715 \\
(3,3)\end{array}$ & $\begin{array}{c}0,208 \\
(2,2)\end{array}$ & $\begin{array}{c}0,351 \\
(2,2)\end{array}$ & $\begin{array}{c}0,562 \\
(2,2)\end{array}$ & $\begin{array}{c}0,787 \\
(2,2)\end{array}$ \\
\hline \multirow{2}{*}{3,3} & $\begin{array}{c}1,053 \\
(7,7)\end{array}$ & $\begin{array}{c}0,570 \\
(3,3)\end{array}$ & $\begin{array}{c}0,570 \\
(3,3)\end{array}$ & $\begin{array}{c}0,684 \\
(2,2)\end{array}$ & $\begin{array}{c}0,844 \\
(2,2)\end{array}$ & $\begin{array}{c}1,053 \\
(2,2)\end{array}$ \\
\hline \multirow{2}{*}{4,4} & $\begin{array}{c}1,526 \\
(7,7)\end{array}$ & $\begin{array}{c}0,605 \\
(4,4)\end{array}$ & $\begin{array}{c}0,671 \\
(4,4)\end{array}$ & $\begin{array}{c}0,991 \\
(4,4)\end{array}$ & $\begin{array}{c}0,998 \\
(4,4)\end{array}$ & $\begin{array}{c}1,127 \\
(4,4)\end{array}$ \\
\hline \multirow{2}{*}{6,6} & $\begin{array}{c}0,706 \\
(7,7)\end{array}$ & $\begin{array}{c}0,801 \\
(6,6)\end{array}$ & $\begin{array}{c}0,706 \\
(6,6)\end{array}$ & $\begin{array}{c}0,742 \\
(6,6)\end{array}$ & $\begin{array}{c}0,859 \\
(6,6)\end{array}$ & $\begin{array}{c}1,056 \\
(2,2)\end{array}$ \\
\hline \multirow{2}{*}{7,7} & $\begin{array}{c}0,902 \\
(7,7)\end{array}$ & $\begin{array}{c}0,626 \\
(7,7)\end{array}$ & $\begin{array}{c}0,647 \\
(7,7)\end{array}$ & $\begin{array}{c}0,881 \\
(7,7)\end{array}$ & $\begin{array}{c}0,917 \\
(7,7)\end{array}$ & $\begin{array}{c}1,062 \\
(7,7 ; \\
2,2)\end{array}$ \\
\hline
\end{tabular}


"Сучасні технології та методи розрахунків у будівництві", випуск 11, 2019

Таблиця 2

Відносний прогин в вузлах розрахункової моделі оболонки

\begin{tabular}{|c|c|c|c|c|c|c|}
\hline \multirow{3}{*}{$\begin{array}{c}\text { Вузол } \\
\text { центру } \\
\text { вм'ятини } \\
(\mathrm{i}, \mathrm{j})\end{array}$} & \multicolumn{3}{|c|}{$\begin{array}{c}\text { Відносний додатковий } \\
\text { прогин }\end{array}$} & \multicolumn{3}{|c|}{$\begin{array}{c}\text { Вузол з максимальним } \\
\text { прогином }\end{array}$} \\
\hline & \multicolumn{3}{|c|}{ Кривина } & \multicolumn{3}{|c|}{ Кривина } \\
\hline & 26 & 120 & 600 & 26 & 120 & 600 \\
\hline немає & 0,137 & 0,134 & 0,193 & 7,7 & 4,4 & 7,7 \\
\hline 2,2 & 0,133 & 0,123 & 0,206 & 7,7 & 3,3 & 2,2 \\
\hline 2,3 & 0,135 & 0,171 & 0,208 & 7,7 & 2,3 & 2,3 \\
\hline 2,4 & 0,154 & 0,172 & 0,204 & 7,7 & 2,4 & 3,4 \\
\hline 2,5 & 0,186 & 0,155 & 0,197 & 7,7 & 2,5 & 3,5 \\
\hline 2,6 & 0,205 & 0,143 & 0,193 & 7,7 & 2,6 & 3,6 \\
\hline 2,7 & 0,165 & 0,160 & 0,199 & 7,7 & 3,7 & 3,7 \\
\hline 3,3 & 0,126 & 0,253 & 0,225 & 7,7 & 3,3 & 3,3 \\
\hline 3,4 & 0,135 & 0,267 & 0,230 & 7,7 & 3,4 & 3,4 \\
\hline 3,5 & 0,151 & 0,236 & 0,222 & 7,7 & 3,5 & 3,5 \\
\hline 3,6 & 0,169 & 0,210 & 0,214 & 7,7 & 3,6 & 3,6 \\
\hline 3,7 & 0,158 & 0,246 & 0,221 & 7,7 & 3,7 & 3,7 \\
\hline 4,4 & 0,124 & 0,260 & 0,237 & 7,7 & 4,4 & 4,4 \\
\hline 4,5 & 0,139 & 0,239 & 0,230 & 5,6 & 4,5 & 4,5 \\
\hline 4,6 & 0,188 & 0,216 & 0,225 & 5,7 & 4,6 & 4,6 \\
\hline 4,7 & 0,164 & 0,245 & 0,229 & 5,7 & 4,7 & 4,7 \\
\hline 5,5 & 0,138 & 0,211 & 0,223 & 5,5 & 5,5 & 5,5 \\
\hline 5,6 & 0,211 & 0,198 & 0,219 & 5,7 & 5,6 & 5,6 \\
\hline 5,7 & 0,191 & 0,222 & 0,225 & 6,7 & 5,7 & 5,7 \\
\hline 6,6 & 0,375 & 0,181 & 0,215 & 7,7 & 6,6 & 6,6 \\
\hline 6,7 & 0,282 & 0,204 & 0,220 & 7,7 & 6,7 & 6,7 \\
\hline 7,7 & 0,211 & 0,222 & 0,225 & 7,7 & 7,7 & 7,7 \\
\hline
\end{tabular}

Висновки і перспективи досліджень. Огляд досліджень побудованих оболонкових покрить показує, що необхідно вдосконалити методи їх зведення та ввести обмеження на дефекти отримані в результаті будівництва. Наведені результати числового експерименту по визначенню стійкості оболонки додатної кривини 3 початковими недосконалостями показують вплив цих недосконалостей для різних кривин та різного розташування недосконалостей. 


\section{Список використаних джерел}

1. Коломійчук Г.П. Розрахунок пологих залізобетонних оболонок в нелінійній постановці 3 урахуванням початкових недосконалостей: Автореферат дис. на здоб. вч. ст. канд. техн. наук. - Одеса, 2004. - 24 с.

2. Айзен Б.М. Расчет несущей способности сферических оболочек в условиях кратковременного и длительного действия нагрузки. Автореф. дис... канд. техн. наук. - Одесса, 1985. - 18 с.

3. Recommendation for Reinforced Concrete Shells and Folded Plates, working group hr. 5. IASS. - Madrid, 1979. $-66 \mathrm{p}$.

4. Тонкостенные оболочечные конструкции: теория, эксперимент и проектирование / Сборник трудов. - М.: Машиностроение, 1980. - 607 с.

5. Чуриков Б.В. Учет влияния начальных несовершенств на устойчивость штампованных сферических оболочек / Б.В. Чуриков, Ю.П. Шишалов // Строительная механика и расчет сооружений, 1978. - № 6. - C. 28-31.

6. Людковский А.М. Оценка точности монтажа оболочки покрытия рынка размером 103×103 м в Минске / А.М. Людковский, А.П. Пигин // Пространственные конструкции зданий и сооружений. - М.; Стройиздат, 1985. - Вып.4. - С.82-94.

7. Зильбер Я.М. Фактические геометрические несовершенства железобетонных оболочек покритий положительной кривизны / Я.М. Зильбер // Проблемы надежности в строительном проектировании. - Свердловск: Уралпромстройниипроект, 1972. - С.65-70.

8. Григорян А.А. Величины начальних усилий в двухпоясном металлическом куполе при устранении нормальних и меридиональных погрішностей монтажа / А.А. Григорян, Е.В. Лебедь // Вестник МГСУ, 2016. - №1. - C.44-56.

9. Якушев В.Л. Определение экстремальных критических нагрузок при заданных ограничениях на начальные неправильности / В.Л. Якушев // Вопросы гидродинамики, аэрофизики и прикладной механики. - М.: Изд. МФТИ, 1985. - С.117-123.

10. Тимашев А.С. Рекомендации по расчету подкрепленных оболочек положительной кривизны на устойчивость / А.С. Тимашев. - Свердловск: Уралпромстройниипроект, 1974. - 76с. 